\title{
EDITORIAL
}

\section{Centenário do descobrimento da doença de Chagas: desafios e perspectivas}

O presente trabalho faz referência ao centenário do descobrimento da doença de Chagas, comemorado em 2009. Este fato, considerado um marco importante da história da medicina, ocorreu em 1909 quando Carlos Chagas, através de um relato minucioso, anunciou para a comunidade científica a detecção, em humanos, do protozoário Trypanosoma cruzi, agente causador da doença de Chagas. Foi realizada pesquisa bibliográfica sobre o assunto nos bancos de dados PubMed, SciELO e MEDLINE publicados entre os anos de 1909 e 2009 . Através de uma breve discussão, o presente artigo aborda os principais desafios e as perspectivas relacionadas à situação atual da doença. Com esse estudo, foi possível perceber que grandes desafios ainda permeiam o campo das questões relacionadas à doença de Chagas, mesmo passados 100 anos de sua descoberta. Espera-se com este estudo, instigar trabalhos futuros, a fim de alcançar concretizações de progressos ainda não superados.

\section{BREVE HISTÓRICO DA DOENÇA DE CHAGAS}

Considerada uma das patologias de mais larga distribuição no continente americano, a doença de Chagas completou em 2009 cem anos de seu descobrimento, tido como um grande feito científico de Carlos Justiniano Ribeiro Chagas, ocorrido em 1909, durante expedição à pequena Cidade de Lassance (interior do Estado de Minas Gerais). Conforme ilustrado na célebre frase de Oswaldo Cruz publicada neste mesmo ano, o descobrimento desta moléstia constitui o mais belo exemplo do poder da lógica a serviço da ciência. Nunca até agora, nos domínios das pesquisas biológicas, se tinha feito um descobrimento tão complexo e brilhante e, o que mais, por um só pesquisador.

Este descobrimento majestoso referido por Oswaldo Cruz, considerado um marco da história da medicina, trata-se da tripla descoberta de Carlos Chagas, onde o cientista mineiro descobriu não apenas o vetor (inseto conhecido popularmente como barbeiro - gênero Triatoma) e o agente etiológico da doença (o protozoário Trypanosoma cruzi), como ainda descreveu a patologia da mesma. A divulgação deste marco data de 22 de abril de 1909, quando na ocasião uma nota prévia publicada na revista Brasil Médico anunciava nova espécie mórbida do homem, produzida por um tripanosomo (Trypansoma cruzi) ${ }^{1}$, sendo neste mesmo ano publicado um artigo completo no primeiro volume da revista de Manguinhos, Memórias do Instituto Oswaldo Cruz, o qual tratou do estudo sobre o ciclo evolutivo do T. cruzi ${ }^{2}$. Os méritos desta descoberta são ainda mais evidentes se considerarmos que na ocasião, o cientista brasileiro efetuou suas investigações, destacando os fundamentos da tripanossomíase, individualmente, sem os recursos tecnológicos disponíveis na atualidade. Sem dúvidas, a história da descoberta da doença de Chagas abriga um dos achados mais importantes entre os que dizem respeito a uma protozoose.

Em reconhecimento à sua grandiosa descoberta, Carlos Chagas ganhou, em 1921, o título de doutor honoris causa da Universidade de Harvard, tornando-se o primeiro brasileiro a obtê-lo. Em seguida, igual distinção lhe foi concedida pela Universidade de Paris e, a partir daí, foi distinguido com diversos títulos acadêmicos e honoríficos, entre os quais a Legião de Honra da França no grau de cavaleiro, a mais alta distinção civil francesa. Além disso, foi indicado, em 1921, ao Prêmio Nobel de Medicina, não o tendo recebido por razões mal explicadas em meio à inoportuna polêmica com Afrânio Peixoto e outros membros da Academia Nacional de Medicina, que desde o ano anterior interrogavam a relação causal entre o Trypanosoma cruzi e a doença de Chagas.

\section{DESAFIOS E PERSPECTIVAS}

Após a sua descoberta, um grande número de trabalhos foi conduzido, além de obtida vasta fonte de informações sobre a doença de Chagas nos setores da etiologia, epidemiologia, clínica, diagnóstico, entre outros. Em carta ao editor, Neto \& Pasternak ${ }^{3}$ resumem brevemente a história da descoberta da tripanossomíase, destacando que hábeis, capazes e dignos pesquisadores deram continuidade às investigações da proeminente parasitose. Mesmo correndo o risco de não serem plenamente justos, os autores destacaram ainda alguns nomes de pesquisadores brasileiros importantes que fazem parte da história da doença, entre eles os de Aluízio Prata, Amilcar Vianna Martins, Anis Rassi, Antonio Walter Ferreira, Astolfo Ferraz de Siqueira, Edison Reis Lopes, Emmanuel Dias, Eurico Vilela, Evandro Chagas, Fritz Köberle, Francisco Ferrioli Filho, Humberto de Oliveira Ferreira, João Carlos Pinto Dias, Joffre Marcondes de Rezende, José Lima Pedreira de Freitas, José Rodrigues Coura, Maria Aparecida Shikanai Yasuda, Mario Endsfeld Camargo, Masayuki Okumura, Oswaldo Paulo Forattini, Ricardo Ribeiro dos Santos, Sonia Gumes Andrade, Thales de Brito, Vanize de Oliveira Macêdo, Zigman Brener, Zilton de Araújo Andrade e Francisco da Silva Laranja, entre outros.

Muitos dos esforços dispensados por estes pesquisadores e outros tantos aqui não mencionados, culminaram em junho de 2006, na certificação de reconhecimento da eliminação da transmissão da doença de Chagas pelo principal vetor (Triatoma infestans) e pela via transfusional, dada ao Brasil pela Organização Pan-Americana de Saúde (OPAS) da Organização Mundial da Saúde (OMS). Conforme destacado por Dias ${ }^{4}$, o que fora o sonho maior de Carlos Chagas 
transformou-se em grande feito, um produto da tenacidade de cientistase de milhares de anônimos guardas sanitários, saga iniciada por Emmanuel Dias ${ }^{* 1}$ há mais de 60 anos.

Entretanto, passados 100 anos de sua descoberta, muitos aspectos relacionados à doença de Chagas ainda carecem de esclarecimentos. Conforme destacado por Dias ${ }^{6}$, a doença apresenta importantes aspectos sócio-culturais e político-econômicos que envolvem questões de iniquidade e globalização, que muitas vezes não são considerados. Além disso, a ausência de progressos na etiopatogenia (os quais elucidariam os mecanismos pelos quais o parasito lesa o organismo), na quimioterapia (os quais permitiriam o desenvolvimento de medicamentos aptos a eliminar eficientemente o protozoário etiológico) e na sorologia (os quais possibilitariam o desenvolvimento de técnicas ou provas sorológicas mais confiáveis), constitui, de acordo com Neto \& Pasternak ${ }^{3}$, um dos grandes desafios a serem superados. Isso sem falar que o desenvolvimento de uma vacina contra a doença ainda é considerado algo incipiente e que não há, ainda, uma forma de prevenir a transmissão do parasito por via congênita, sendo consenso que, para esta modalidade, a melhor estratégia é a detecção precoce do caso e seu pronto tratamento ${ }^{7}$.

A infecção humana pode ser muito grave, podendo provocar elevados índices de mortalidade em crianças na sua fase aguda e severo acometimento cardíaco e/ou digestivo em adultos crônicos ${ }^{8}$. Em adição, conforme destacado pela própria $\mathrm{OMS}^{9}$, pode ocasionar perdas sociais importantes nas áreas endêmicas, em termos de mortalidade, absenteísmo, incapacidade laboral e custos médico-sociais, as quais geralmente são ignoradas por políticos e governos, tanto em virtude da evolução crônica e pouca visibilidade da doença, como pelo desconhecimento da população exposta ou afetada pela doença. A $\mathrm{OMS}^{9}$ estima que existam de 12 a 14 milhões de infectados na América Latina, sendo que mais de 60 milhões de pessoas podem estar sob risco de transmissão, em aproximadamente 18 países endêmicos.

Com relação à etiopatogenia da doença de Chagas, pode-se dizer que muitos aspectos ainda são desconhecidos e que múltiplos mecanismos têm sido propostos para explicar a patogênese da doença. No estudo recente de Bonney \& Engman $^{10}$, os autores destacaram que apesar de atualmente muitos estudos relacionarem a patologia da doença de Chagas à persistência do parasito no miocárdio e à autoimunidade, fortes evidências têm demonstrado que outros mecanismos, com efeitos sinérgicos, podem estar ligados à patogênese da moléstia. Conforme aponta Engman \& Leon ${ }^{11}$, a lise da célula hospedeira provocada pelos parasitos, a destruição neuronal primária (a qual ocorre durante a fase aguda da doença e que pode levar a lesões na fase crônica), as alterações microvasculares induzidas pelos parasitos (as quais podem levar à hipoperfusão cardíaca e à degeneração de miócitos), a ativação de células $\mathrm{B}$ policlonais (que ocorre durante a infecção e que pode provocar um descontrole nos mecanismos de imunossupressão e autoimunidade) e a persistência de antígenos de T. cruzi constituem outras hipóteses importantes que podem estar relacionadas com a patologia cardíaca

*Emmanuel Dias, conforme descrito por Dias cols ${ }^{5}$, é considerado um dos mais profícuos seguidores de Carlos Chagas, o qual teve sua vida dedicada intensamente ao estudo, reconhecimento e controle da doença de Chagas. Em trinta anos de atividades, trabalhou exaustivamente em diagnóstico, epidemiologia, clinica e controle. Idealizou estratégias de prospecção, mapeou a doença nas Américas, participou diretamente da sistematização da cardiopatia crônica e descreveu o primeiro inseticida eficaz contra os triatomíneos, também formatando a estratégia de seu controle. Foi recentemente considerado o cientista que teve o maior impacto no enfrentamento desta tripanossomíase em todos os tempos. chagásica. Para Dutra \& Gollob ${ }^{12}$, a compreensão coerente de todas estas hipóteses envolvendo a elucidação dos reais mecanismos relacionados à patogênese da doença é crítica para o desenvolvimento de novas terapias e para intervenções bem sucedidas.

No que tange à quimioterapia da doença de Chagas, dados da literatura demonstram que vários trabalhos foram e têm sido desenvolvidos visando a criação de novas alternativas terapêuticas, indo desde a descoberta de novos alvos bioquímicos até o desenvolvimento de novas moléculas com potente ação tripanossomicida. Entretanto, conforme destacado por Oliveira $\operatorname{cols}^{13}$, o sucesso da terapêutica tem esbarrado em pontos cruciais, tais como: esquema terapêutico prolongado, variabilidade genética dos parasitos, cepas naturalmente resistentes aos fármacos e reações adversas. Em face destes obstáculos, vimos que passado um século do descobrimento da doença de Chagas a busca por uma terapia medicamentosa adequada ao tratamento da doença continua a ser um desafio para muitos pesquisadores. Conforme revisto por Oliveira $\mathrm{cols}^{13}$ e Sobrinho cols ${ }^{14}$, pesquisas promissoras apontam novas moléculas com atividade terapêutica anti-T. cruzi e baixos efeitos tóxicos. Entretanto, ainda há um grande caminho a ser percorrido para que a comunidade científica e as indústrias farmacêuticas tornem disponível no mercado consumidor medicamentos novos, seguros e eficazes. Cabe ainda ressaltar a possibilidade de uma melhor vetorização do princípio ativo atualmente utilizado no combate à doença de Chagas, o benznidazol, de modo que sejam oferecidas aos pacientes alternativas mais adequadas ao tratamento da doença.

Com relação ao desenvolvimento vacinal, apesar de ainda não existir uma vacina eficaz contra a doença de Chagas, sabe-se, por meio de estudos que usaram diferentes formulações vacinais, que uma resposta complexa é requerida para o controle do parasito, envolvendo anticorpos líticos, citocinas de perfil Th1 e linfócitos $\mathrm{T}$ citotóxicos. Conforme destacado no estudo de Dumonteil ${ }^{15}$, atualmente muitos estudos têm focado nos antígenos recombinantes e nas vacinas de DNA, sendo que os antígenos candidatos mais importantes são: as proteínas cruzipaina, trans-sialidase, proteínas de superfície de formas amastigotas, proteína Rod paraflagelar, entre outros ${ }^{16}$. Além disso, Cazorla cols ${ }^{16}$ destacam que nos últimos cinco anos, trabalhos experimentais têm sido conduzidos, visando analisar o sistema delivery de DNA, incluindo vírus e bactérias, assim como imunomodulatórios (tais como CpG-oligodesoxinucleotídeos, glicolipídeos alfagalactosilceramida), citocinas (como a IL-12) e quimiocinas. Entretanto, apesar de muitos trabalhos terem demonstrado algum grau de proteção através dos imunobiológicos utilizados, testados sobretudo em camundongos, avaliações adicionais em outros modelos experimentais, tais como em cães e primatas não-humanos ainda apresentam caráter incipiente. Além disso, é possível observar que apesar dos avanços na compreensão da imunopatogenia da doença de Chagas e aporte tecnológico para desenvolvimento de vacinas, os resultados dos experimentos mantém-se semelhantes aos revisados há duas décadas por Brener ${ }^{17}$, fato este que evidencia ainda mais a necessidade de maiores investimentos neste campo de pesquisa.

\section{CONSIDERAÇÕES FINAIS}

Baseado no que foi exposto, é possível perceber que grandes desafios ainda permeiam o campo das questões relacionadas à doença de Chagas, mesmo passados 100 anos de sua descoberta. Conforme discutido no trabalho de Dias ${ }^{5}$, várias situações devem ser levadas em 
consideração, permitindo explorar melhor os aspectos necessários ao entendimento das questões ainda obscuras ou negligenciadas da doença de Chagas, dentre as quais se destacam: I) as relacionadas às leis de mercado, à economia em escala e às diversas situações de injustiça que inviabilizam o modelo agrícola e artesanal de pequenos produtores rurais, repercutindo diretamente em questões básicas da expansão da tripanossomíase; II) as condições habitacionais precárias e primitivas (ainda observadas em regiões menos privilegiadas), as quais relaciona-se diretamente com a permanência do inseto vetor nas moradias rurais; III) a questão educacional, a qual deve, sobretudo, desestimular o sistema educativo elitista e pouco voltado para questões sociais, o que de certa forma, acentua o desinteresse pela doença e IV) a questão investigativa.

Sobre esta última questão, Dias ${ }^{5}$ ressalta a existência da visível perda de prioridade e de financiamento para os temas da doença de Chagas, especialmente os de natureza aplicada, em agências e instituições de fomento, e ainda mais nas indústrias. Outros temas como agravos crônico-degenerativos e pesquisas de ponta com sofisticados aparatos de biologia molecular têm mais aceitação em periódicos indexados, ou geram maiores lucros pecuniários ou políticos, sendo considerados principais e de maior impacto pelos periódicos científicos em geral. Conforme discutido por Dias cols ${ }^{18}$, Vieira ${ }^{19}$ e Jorg \& Storino ${ }^{20}$, e sintetizado por Dias cols ${ }^{5}$, "muitas vezes se desestimulam investigações de terreno sobre o controle da transmissão e o manejo de infectados pelo $T$. cruzi sob a alegação de que o produto resultante terá extrema dificuldade de publicação e que o peso curricular do trabalho será muito baixo em termos acadêmicos, e, portanto, desvantajoso ao aplicante que pretende competir cientificamente e galgar postos em sua carreira”.

Todos esses aspectos são muito importantes e merecem atenção, tanto por parte dos pesquisadores quanto por parte dos órgãos responsáveis pelos financiamentos concedidos às pesquisas, para que na comemoração do próximo século da doença de Chagas muitos desafios atuais já estejam superados.

\section{REFERÊNCIAS}

1. Chagas C. Nova espécie mórbida do homem, produzida por um tripanossomo Trypanosoma cruzi. Braz Med 1909; XXIII: 16.

2. Chagas C. Nova tripanossomíase humana. Estudos sobre a morfologia e o ciclo evolutivo do Schizotrypanum cruzi n. gen., n. sp., agente etiológico de nova entidade mórbida do homem. Mem Inst Oswaldo Cruz 1909; 1:159-218.

3. Neto VA, PasternakJ. Centenário da doença de Chagas. Rev Saude Publica 2009; 43:381-382.
4. Dias JCP. Doença de Chagas: sucessos e desafios. Cad Saude Publica 2006; 22:2020.

5. Dias JCP. Globalização, iniquidade e doença de Chagas. Cad Saude Publica 2007; 23:S13-S22.

6. Dias JCP, Prata A, Coura JR. Emmanuel Dias: o principal artífice do combate à doença de Chagas nas Américas. Rev Soc Bras Med Trop 2008; 41:502-504.

7. Secretaria de Vigilância em Saúde. Ministério da Saúde. Consenso brasileiro em doença de Chagas. Rev Soc Bras Med Trop 2005; 38(supl 3):7-29.

8. DiasJCP, Macedo VO. Doença de Chagas. In: Coura JR, editor. Dinâmica das doenças infecciosas e parasitárias. Rio de Janeiro: Guanabara Koogan Editora; 2005.

9. World Health Organization (WHO). Control of Chagas disease. Geneva: World Health Organization; 2002.

10. Bonney KM, Engman DM. Chagas heart disease pathogenesis: one mechanism or many? Curr Mol Med 2008; 8:510-518.

11. Engman DM,Leon JS. Pathogenesis of Chagas heart disease: role of autoimmunity. Acta Tropica 2002; 81:123-132.

12. Dutra WO, Gollob KJ. Current concepts in immunoregulation and pathology of human Chagas disease. Curr Opin Infect Dis 2008; 21:287-292.

13. Oliveira MF, Nagao-Dias AT, Pontes MO, Souza-Júnior AS, Coelho HLL, Coelho ICB. Tratamento etiológico da doença de Chagas no Brasil. Rev Patol Trop 2008; 37:209-228.

14. Sobrinho JLS, Medeiros FPM, La-Roca MF, Silva KER, Lima LNA, Neto PJR Delineamento de alternativas terapêuticas para o tratamento da doença de Chagas. Rev Patol Trop 2007; 36:103-118.

15. Dumonteil E. Vaccine development against Trypanosoma cruzi and Leishmania species in the post-genomic era. Infect Gen Evol 2009; 9:1075-1082.

16. Cazorla SI, Frank FM, Malchiodi EL. Vaccination approaches against Trypanosoma cruzi infection. Expert Rev Vaccines 2009; 8:921-935.

17. Brener Z. Why vaccines do not work in Chagas disease. Parasitol Today 1986; 2:196-197.

18. Dias JCP. Doença de Chagas e a questão da tecnologia. Bol Oficina Sanit Panam 1985; 99:244-257.

19. Vieira C. Globalización, comercio internacional y equidad en materia de salud. Rev Panam Salud Pública 2002; 11:425-429.

20. Jörg M, Storino RA. La enfermedad de Chagas em el siglo XXI: consenso para una asignatura pendiente. Consenso Argentino sobre la Enfermedad de Chagas. Rev Argent Cardiol 2002; 70:9-10.

\section{Guilherme Malafaia ${ }^{1}$}

\section{Aline Sueli de Lima Rodrigues ${ }^{2,3}$}

1. Departamento de Áreas Academicas, Instituto Federal de Educação, Ciencia e Tecnologia de Goiás, Campus Anápolis, GO. 2. Laboratório de Ciências Ambientais, Instituto de Educação, Ciência e Tecnologia Goiano, Urutaí, GO. 3. Departamento de Geologia, Programa de Pós-Graduação em Evolução Crustal e Conservação de Recursos Naturais, Universidade Federal de Ouro Preto, Ouro Preto, MG. e-mail: guilherme@nupeb.ufop.br; aline@degeo.ufop.br 